\title{
Body-Mass Index and Mortality among Adults with Incident Type 2 Diabetes
}

\section{Citation}

Tobias, Deirdre K., An Pan, Chandra L. Jackson, Eilis J. O'Reilly, Eric L. Ding, Walter C. Willett, JoAnn E. Manson, and Frank B. Hu. 2014. "Body-Mass Index and Mortality Among Adults with Incident Type 2 Diabetes." N Engl J Med 370 (3) (January 16): 233-244. doi:10.1056/ nejmoa1304501.

\section{Published Version}

doi:10.1056/NEJMoa1304501

\section{Permanent link}

http://nrs.harvard.edu/urn-3:HUL.InstRepos:28714462

\section{Terms of Use}

This article was downloaded from Harvard University's DASH repository, and is made available under the terms and conditions applicable to Other Posted Material, as set forth at http:// nrs.harvard.edu/urn-3:HUL.InstRepos:dash.current.terms-of-use\#LAA

\section{Share Your Story}

The Harvard community has made this article openly available.

Please share how this access benefits you. Submit a story.

\section{Accessibility}




\title{
Body-Mass Index and Mortality among Adults with Incident Type 2 Diabetes
}

\author{
Deirdre K. Tobias, Sc.D., An Pan, Ph.D., Chandra L. Jackson, Ph.D., \\ Eilis J. O'Reilly, Sc.D., Eric L. Ding, Sc.D., Walter C. Willett, M.D., Dr.P.H., \\ JoAnn E. Manson, M.D., Dr.P.H., and Frank B. Hu, M.D., Ph.D.
}

ABSTRACT

\section{BACKGROUND}

The relation between body weight and mortality among persons with type 2 diabetes remains unresolved, with some studies suggesting decreased mortality among overweight or obese persons as compared with normal-weight persons (an "obesity paradox").

\section{METHODS}

We studied participants with incident diabetes from the Nurses' Health Study (8970 participants) and Health Professionals Follow-up Study (2457 participants) who were free of cardiovascular disease and cancer at the time of a diagnosis of diabetes. Body weight shortly before diagnosis and height were used to calculate the body-mass index (BMI, the weight in kilograms divided by the square of the height in meters). Multivariable Cox models were used to estimate the hazard ratios and $95 \%$ confidence intervals for mortality across BMI categories.

\section{RESULTS}

There were 3083 deaths during a mean period of 15.8 years of follow-up. A J-shaped association was observed across BMI categories (18.5 to 22.4, 22.5 to 24.9 [reference], 25.0 to $27.4,27.5$ to $29.9,30.0$ to 34.9 , and $\geq 35.0$ ) for all-cause mortality (hazard ratio, 1.29 [95\% confidence interval $\{\mathrm{CI}\}, 1.05$ to 1.59 ] $1.00 ; 1.12$ [95\% CI, 0.98 to 1.29]; 1.09 [95\% CI, 0.94 to 1.26]; 1.24 [95\% CI, 1.08 to 1.42]; and 1.33 [95\% CI, 1.14 to 1.55], respectively). This relationship was linear among participants who had never smoked (hazard ratios across BMI categories: 1.12, 1.00, 1.16, 1.21, 1.36, and 1.56, respectively) but was nonlinear among participants who had ever smoked (hazard ratios across BMI categories: 1.32, 1.00, 1.09, 1.04, 1.14, and 1.21) $(\mathrm{P}=0.04$ for interaction). A direct linear trend was observed among participants younger than 65 years of age at the time of a diabetes diagnosis but not among those 65 years of age or older at the time of diagnosis ( $\mathrm{P}<0.001$ for interaction).

\section{CONCLUSIONS}

We observed a J-shaped association between BMI and mortality among all participants and among those who had ever smoked and a direct linear relationship among those who had never smoked. We found no evidence of lower mortality among patients with diabetes who were overweight or obese at diagnosis, as compared with their normal-weight counterparts, or of an obesity paradox. (Funded by the National Institutes of Health and the American Diabetes Association.)
From the Departments of Nutrition (D.K.T., A.P., C.L.J., E.J.O., E.L.D., W.C.W., F.B.H.) and Epidemiology (W.C.W., J.E.M., F.B.H.), Harvard School of Public Health, and the Channing Division of Network Medicine (E.J.O., E.L.D., W.C.W., F.B.H.) and the Division of Preventive Medicine (J.E.M.), Department of Medicine, Brigham and Women's Hospital and Harvard Medical School - all in Boston; and Saw Swee Hock School of Public Health and Yong Loo Lin School of Medicine, National University of Singapore and National University Health System, Singapore (A.P.). Address reprint requests to Dr. Tobias at the Department of Nutrition, Harvard School of Public Health, 665 Huntington Ave., Boston, MA 02115, or at dbanel@ hsph.harvard.edu; or to Dr. Pan at the Saw Swee Hock School of Public Health, National University of Singapore, 16 Medical Dr., MD3, Singapore 117597, or at ephanp@ nus.edu.sg.

Drs. Tobias and Pan contributed equally to this article.

This article was updated on April 3, 2014, at NEJM.org.

N Engl J Med 2014;370:233-44. DOI: 10.1056/NEJMoal304501 Copyright (@) 2014 Massachusetts Medical Society. 
E XCESS ADIPOSITY IS A WELL-ESTABLISHED risk factor for premature death in the general population, including death due to cardiovascular disease or cancer. ${ }^{1-4}$ However, a so-called obesity paradox (i.e., an association between obesity, as compared with normal weight, and reduced mortality) has been reported among patients with heart failure, end-stage renal disease, or hypertension, and, recently, among those with type 2 diabetes. ${ }^{5-12}$ Most of these studies, however, have been limited by small samples and suboptimal control for smoking status and preexisting chronic conditions.

Smoking is a concern in analyses of body weight and mortality because it is associated with decreased body weight but an increased risk of death. ${ }^{13}$ Statistical adjustment for smoking status (e.g., ever smoked vs. never smoked) is often insufficient to control for varying degrees of smoking duration and intensity. Thus, stratification according to smoking status can be an important way to examine the association between body weight and the risk of death; in addition, the subgroup analysis among persons who have never smoked can reduce residual bias related to smoking. ${ }^{3,4,13-15}$ An additional concern is reverse causation, whereby underlying chronic disease or frailty both causes weight loss and elevates the risk of death. Exclusion of persons with known illnesses at baseline and censoring of data for patients who died early in the follow-up period are routinely performed to reduce this bias. ${ }^{16}$

To address the limitations of previous analyses, we conducted a detailed analysis of the association between body-mass index (BMI) and the risk of death among participants with incident diabetes from two large prospective cohort studies, the Nurses' Health Study (NHS) and the Health Professionals Follow-up Study (HPFS).

\section{METHODS}

\section{STUDY POPULATION}

The NHS was initiated in 1976 with the enrollment of 121,700 female nurses 30 to 55 years of age. The HPFS began in 1986, enrolling 51,529 male health professionals between 40 and 75 years of age. Questionnaires are administered biennially to update medical, lifestyle, and other health-related information. ${ }^{17,18}$ Cumulative follow-up exceeds $90 \%$ of potential person-time for both cohorts.

Our analyses included women and men report- ing incident diabetes between baseline (1976 for the NHS and 1986 for the HPFS) and January 1, 2010 (Fig. S1 in the Supplementary Appendix, available with the full text of this article at NEJM.org). We excluded participants reporting a history of diabetes at baseline or reporting cardiovascular disease (stroke, coronary heart disease, or coronaryartery bypass graft surgery) or cancer before a diabetes diagnosis. Participants were excluded if they were underweight (BMI [the weight in kilograms divided by the square of height in meters] $<18.5$, because of limited statistical power for this group), had received a diagnosis of diabetes before 35 years of age (probably type 1 diabetes), or did not report body weight on the relevant questionnaire. The study protocol was approved by the institutional review boards of Brigham and Women's Hospital and the Harvard School of Public Health, with participants' consent implied by the return of the questionnaires. The first, second, and last authors take complete responsibility for the integrity of the data and the accuracy of the data analysis.

\section{ASSESSMENT OF TYPE 2 DIABETES}

Participants reporting a physician's diagnosis of diabetes on the biennial questionnaire were mailed a supplemental questionnaire. Confirmed cases were defined according to the National Diabetes Data Group classification, ${ }^{19}$ updated in June 1998 to adopt a new threshold for a fasting plasma glucose level of at least $126 \mathrm{mg}$ per deciliter $\left(7.0 \mathrm{mmol}\right.$ per liter). ${ }^{20}$ Validation studies with the use of medical records for 62 NHS participants $^{21}$ and 59 HPFS participants ${ }^{22}$ showed very high accuracy of our classification $(98 \%$ and $97 \%$, respectively).

\section{ASSESSMENT OF BODY-MASS INDEX}

Body weight was updated every 2 years by questionnaire. Weight at diagnosis was estimated from the most recent questionnaire before the diagnosis (mean time from questionnaire to diagnosis, 11 months). Self-reported weight was previously validated in a subgroup of 140 NHS participants and 123 HPFS participants $(<1 \%$ of all participants) living in the Boston area, on the basis of the correlation between technician-measured and self-reported weight (Spearman correlation coefficient, 0.97 for both NHS and HPFS participants; mean difference [self-reported weight minus measured weight], $-1.50 \mathrm{~kg}$ for NHS participants and $-1.06 \mathrm{~kg}$ for HPFS participants). ${ }^{23}$ A sensitivity 
analysis assessed the potential effect of error in self-reported weight and height with the use of the sex-specific calibration equations proposed by Berrington de Gonzalez et al. ${ }^{3}$ from the U.S. National Health and Nutrition Evaluation Survey sample $\left(\mathrm{BMI}_{\text {measured }}=0.63+\left[1.01 \times \mathrm{BMI}_{\text {self-reported }}\right]+\right.$ $[0.0006 \times$ age in years] for women and $0.29+$ $\left[0.98 \times \mathrm{BMI}_{\text {self-reported }}\right]+[0.012 \times$ age in years $]$ for men).

\section{ASCERTAIN MENT OF DEATHS}

The primary outcome was death from any cause through January 1, 2012. Most deaths ( $>98 \%$ ) were identified from reports by the next of kin or postal authorities or from searches of the National Death Index. ${ }^{24,25}$ The cause of death was determined by physician review of medical records and death certificates. The diagnostic codes of the International Classification of Diseases, 8th Revision (ICD-8), were used to classify deaths as due to cardiovascular disease (ICD-8 codes 390 through 459 and 795), cancer (ICD-8 codes 140 through 207), or other causes.

\section{ASSESSMENT OF COVARIABLES}

Detailed information on cigarette smoking, physical activity, menopausal status (for NHS participants only), and several lifestyle factors and health outcomes were updated every 2 years. Marital status and status with respect to a family history of diabetes were assessed periodically. Dietary information was collected from validated foodfrequency questionnaires approximately every 4 years. Diet quality was assessed with the use of the 2010 Alternate Healthy Eating Index (with scores ranging from 2.5 to 87.5 and higher scores indicating a healthier diet). ${ }^{26}$ The covariables were derived from the most recent questionnaire before a diabetes diagnosis.

\section{STATISTICAL ANALYSIS}

Hazard ratios and 95\% confidence intervals were estimated from Cox proportional-hazards models, with number of months since a diabetes diagnosis as the time scale. Person-time was calculated from the date of a diabetes diagnosis until death or the end of follow-up (January 1, 2012). BMI categories were defined as follows: 18.5 to 22.4 , 22.5 to 24.9 (reference), 25.0 to $27.4,27.5$ to 29.9 , 30.0 to 34.9 , and 35.0 or higher. Multivariable models were adjusted for race or ethnic group (white, black, Asian American, Hispanic, or other), smoking status (never smoked; previously smoked; currently smokes 1 to 14,15 to 24 , or $\geq 25$ cigarettes per day; or not reported), alcohol consumption (women: $0,0.1$ to $4.9,5.0$ to 14.9 , or $\geq 15.0$ g per day; men: $0,0.1$ to $4.9,5.0$ to 29.9 , or $\geq 30.0$ g per day), physical activity ( $<3.0,3.0$ to $8.9,9.0$ to $17.9,18.0$ to 26.9 , or $\geq 27.0$ hours of metabolic-equivalent tasks per week), marital status (married or unmarried), diet quality (in quintiles of Alternate Healthy Eating Index scores), family history of diabetes (yes or no), and menopausal status (for NHS participants only). The P values for linear trend were computed by modeling BMI as a continuous variable. Nonlinear trends were assessed with likelihood-ratio tests of restricted cubic splines. ${ }^{27}$ A P value of less than 0.05 was considered to indicate a significant linear or nonlinear trend. The hazard-ratio estimates for the two cohorts were combined with the use of fixed-effect metaanalyses with inverse-variance weighting.

We repeated our analyses with stratification according to baseline smoking status and with early deaths ( $<4$ years after diagnosis) excluded. Effect modification by smoking status (never smoked vs. ever smoked) and age at diagnosis ( $<65$ years vs. $\geq 65$ years) was estimated from the multiplicative interaction term between continuous BMI and the effect modifier added to the main effects model. The proportional-hazards assumption was evaluated with a likelihood-ratio test comparing the model with and without an interaction term between time period and BMI category. Data were analyzed with the use of SAS software, version 9.2 (SAS Institute), at a two-tailed alpha level of 0.05 .

\section{RESULTS}

\section{STUDY PARTICIPANTS}

For the 11,427 participants included in our analysis, the mean age at diabetes diagnosis was 62 years (range, 35 to 86) among the 8970 NHS participants and 64 years (range, 41 to 91) among the 2457 HPFS participants. Baseline characteristics are presented in Table 1, stratified according to BMI categories. A higher BMI at diagnosis was inversely associated with age at diagnosis, physical activity, and Alternate Healthy Eating Index score. The lowest BMI category (18.5 to 22.4) had the highest prevalence of current smokers, and normal-weight participants (BMI, 18.5 to 24.9) were more likely to have lost weight before diagnosis than overweight participants (BMI, 25.0 to 29.9) and obese participants (BMI, $\geq 30$ ). 


\section{ALL-CAUSE MORTALITY}

A total of 3083 deaths from all causes were observed over a mean follow-up of 15.8 years, with a maximum follow-up of 36 years among women (mean, 16.2 years; 16.1 deaths per 1000 personyears) and 26 years among men (mean, 14.5 years; 21.8 deaths per 1000 person-years). The mean $( \pm S D)$ age at death was $74.6 \pm 7.8$ years for women and $78.7 \pm 8.7$ years for men. In general, crude rates of death were higher among participants who had ever smoked than among those who had never smoked, across BMI categories (Table 2).

A J-shaped association between BMI and allcause mortality was observed among all the participants (Table 2) $(\mathrm{P}<0.001$ for nonlinearity among NHS participants; $\mathrm{P}=0.59$ among HPFS partici- pants). As compared with participants with a BMI of 22.5 to 24.9, those in the lowest BMI category, 18.5 to 22.4, had a significantly elevated all-cause mortality (hazard ratio, 1.29; 95\% confidence interval [CI], 1.05 to 1.59), as did those in the highest BMI categories (BMI of 30.0 to 34.9: hazard ratio, 1.24 ; $95 \% \mathrm{CI}, 1.08$ to 1.42 ; $\mathrm{BMI} \geq 35.0$ : hazard ratio, 1.33; 95\% CI, 1.14 to 1.55 ).

Results indicated significant effect modification according to smoking status (Table 2) $(\mathrm{P}=0.04$ for interaction), with divergent trends in the risk of death across BMI strata for participants who had ever smoked as compared with those who had never smoked. A significant linear trend was seen among participants who had never smoked $(\mathrm{P}<0.001)$, with no evidence of a nonlin-

\begin{tabular}{|c|c|c|c|c|c|c|}
\hline \multirow[t]{2}{*}{ Characteristic } & \multicolumn{6}{|c|}{ BMI Category } \\
\hline & $18.5-22.4$ & $22.5-24.9$ & $25.0-27.4$ & $27.5-29.9$ & $30.0-34.9$ & $\geq 35.0$ \\
\hline \multicolumn{7}{|l|}{ NHS cohort: women } \\
\hline No. of participants & 362 & 737 & 1465 & 1452 & 2740 & 2214 \\
\hline $\begin{array}{l}\text { Age at the questionnaire return before diabetes } \\
\text { diagnosis (yr) }\end{array}$ & $63.2 \pm 11.0$ & $62.8 \pm 10.2$ & $62.7 \pm 9.2$ & $62.4 \pm 8.8$ & $60.7 \pm 8.6$ & $58.3 \pm 8.4$ \\
\hline Age at diabetes diagnosis (yr) & $64.4 \pm 11.1$ & $63.9 \pm 10.2$ & $63.9 \pm 9.2$ & $63.6 \pm 8.8$ & $61.9 \pm 8.6$ & $59.5 \pm 8.4$ \\
\hline BMI & $21.3 \pm 1.0$ & $23.9 \pm 0.7$ & $26.5 \pm 0.8$ & $28.9 \pm 0.6$ & $32.3 \pm 1.4$ & $39.4 \pm 3.2$ \\
\hline Physical activity (MET-hr/wk) & $16.9 \pm 20.7$ & $16.5 \pm 27.6$ & $15.6 \pm 24.1$ & $13.7 \pm 18.7$ & $12.2 \pm 17.0$ & $8.7 \pm 13.3$ \\
\hline Alcohol intake (g/day) & $5.7 \pm 10.7$ & $5.3 \pm 9.5$ & $4.0 \pm 8.5$ & $3.6 \pm 7.9$ & $2.8 \pm 6.7$ & $2.1 \pm 6.5$ \\
\hline Alternate Healthy Eating Index score $†$ & $53.0 \pm 11.7$ & $52.9 \pm 10.9$ & $51.9 \pm 10.7$ & $51.8 \pm 11.0$ & $50.4 \pm 10.6$ & $48.9 \pm 10.5$ \\
\hline Change in BMI during $2 \mathrm{yr}$ before diabetes diagnosis & $-0.1 \pm 2.6$ & $0.4 \pm 3.1$ & $0.8 \pm 3.7$ & $1.4 \pm 4.4$ & $1.7 \pm 5.4$ & $2.9 \pm 7.1$ \\
\hline $\begin{array}{l}\text { Reduction in BMI of }>1 \text { unit during } 2 \text { yr before diabetes } \\
\text { diagnosis (\%) }\end{array}$ & 21.9 & 18.9 & 19.8 & 16.5 & 18.2 & 16.7 \\
\hline White race $(\%) \div$ & 93.9 & 94.6 & 95.2 & 94.8 & 96.0 & 96.3 \\
\hline One or more symptoms of diabetes at diagnosis (\%) & 35.4 & 34.7 & 37.9 & 40.6 & 39.6 & 44.2 \\
\hline Insulin use in first yr after diagnosis (\%) & 7.7 & 8.1 & 8.1 & 6.3 & 7.4 & 8.4 \\
\hline Postmenopausal (\%) & 77.9 & 78.0 & 78.8 & 79.7 & 76.2 & 69.3 \\
\hline \multicolumn{7}{|l|}{ Smoking status (\%) } \\
\hline Never smoked & 43.4 & 43.8 & 45.7 & 43.9 & 44.6 & 45.5 \\
\hline Former smoker & 34.3 & 38.3 & 37.8 & 41.0 & 41.6 & 43.2 \\
\hline \multicolumn{7}{|l|}{ Current smoker } \\
\hline$<15$ cigarettes/day & 14.4 & 13.6 & 12.8 & 10.6 & 9.9 & 8.0 \\
\hline$\geq 15$ cigarettes/day & 7.5 & 4.3 & 3.3 & 4.5 & 3.7 & 3.0 \\
\hline Unknown & 0.6 & 0.0 & 0.4 & 0.1 & 0.2 & 0.3 \\
\hline Married (\%) & 67.7 & 71.2 & 69.8 & 69.8 & 70.9 & 70.0 \\
\hline Family history of diabetes (\%) & 44.8 & 49.3 & 48.2 & 47.9 & 48.4 & 46.8 \\
\hline Hypercholesterolemia (\%) & 33.2 & 37.7 & 41.3 & 37.6 & 35.3 & 30.2 \\
\hline High blood pressure (\%) & 35.4 & 38.9 & 42.8 & 45.8 & 50.0 & 49.0 \\
\hline
\end{tabular}




\begin{tabular}{|c|c|c|c|c|c|c|}
\hline \multirow[t]{2}{*}{ Characteristic } & \multicolumn{6}{|c|}{ BMI Category } \\
\hline & $18.5-22.4$ & $22.5-24.9$ & $25.0-27.4$ & $27.5-29.9$ & $30.0-34.9$ & $\geq 35.0$ \\
\hline \multicolumn{7}{|l|}{ HPFS cohort: men } \\
\hline No. of participants & 64 & 337 & 630 & 558 & 620 & 248 \\
\hline $\begin{array}{l}\text { Age at the questionnaire return before diabetes } \\
\text { diagnosis (yr) }\end{array}$ & $68.0 \pm 9.3$ & $66.5 \pm 9.2$ & $64.1 \pm 8.5$ & $63.5 \pm 8.3$ & $61.1 \pm 8.0$ & $58.6 \pm 7.8$ \\
\hline Age at diabetes diagnosis (yr) & $69.2 \pm 9.3$ & $67.6 \pm 9.2$ & $65.2 \pm 8.5$ & $64.6 \pm 8.2$ & $62.3 \pm 8.1$ & $59.7 \pm 7.7$ \\
\hline BMI & $21.4 \pm 1.0$ & $23.9 \pm 0.6$ & $26.2 \pm 0.8$ & $28.7 \pm 0.7$ & $32.0 \pm 1.4$ & $38.5 \pm 3.6$ \\
\hline Physical activity (MET-hours/wk) & $34.0 \pm 39.0$ & $32.0 \pm 33.4$ & $28.2 \pm 31.4$ & $27.0 \pm 35.8$ & $24.9 \pm 36.0$ & $17.8 \pm 25.1$ \\
\hline Alcohol intake (g/day) & $10.1 \pm 14.8$ & $8.8 \pm 12.3$ & $10.1 \pm 14.1$ & $10.8 \pm 16.8$ & $10.0 \pm 15.1$ & $7.2 \pm 12.1$ \\
\hline Alternate Healthy Eating Index score ${ }^{\dagger}$ & $53.7 \pm 12.7$ & $55.6 \pm 12.2$ & $53.8 \pm 11.7$ & $52.8 \pm 11.3$ & $51.9 \pm 10.9$ & $51.0 \pm 10.8$ \\
\hline Change in BMI during $2 \mathrm{yr}$ before diabetes diagnosis & $-0.4 \pm 1.3$ & $-0.3 \pm 1.0$ & $-0.1 \pm 1.3$ & $0.1 \pm 1.3$ & $0.3 \pm 1.9$ & $0.8 \pm 2.2$ \\
\hline $\begin{array}{c}\text { Reduction in } \mathrm{BMI} \text { of }>1 \text { unit in } 2 \mathrm{yr} \text { before diabetes } \\
\text { diagnosis (\%) }\end{array}$ & 23.5 & 19.2 & 16.9 & 14.9 & 17.1 & 15.5 \\
\hline White race $(\%)+$ & 90.6 & 89.0 & 93.2 & 94.6 & 94.5 & 95.2 \\
\hline One or more symptoms of diabetes at diagnosis (\%) & 43.8 & 40.4 & 45.9 & 49.1 & 51.9 & 59.3 \\
\hline Insulin use in first yr after diagnosis (\%) & 4.7 & 1.2 & 2.4 & 2.3 & 2.1 & 2.4 \\
\hline \multicolumn{7}{|l|}{ Smoking status (\%) } \\
\hline Never smoked & 40.6 & 40.7 & 37.9 & 38.4 & 42.3 & 45.6 \\
\hline Former smoker & 40.6 & 47.5 & 51.3 & 52.0 & 47.6 & 46.8 \\
\hline \multicolumn{7}{|l|}{ Current smoker } \\
\hline$<15$ cigarettes/day & 12.5 & 8.0 & 5.4 & 3.6 & 5.2 & 1.6 \\
\hline$\geq 15$ cigarettes/day & 3.1 & 1.5 & 2.2 & 2.0 & 2.3 & 2.4 \\
\hline Unknown & 3.1 & 2.4 & 3.2 & 4.1 & 2.7 & 3.6 \\
\hline Married (\%) & 84.4 & 83.7 & 81.3 & 80.5 & 81.6 & 77.0 \\
\hline Family history of diabetes (\%) & 40.6 & 50.5 & 50.8 & 48.2 & 49.8 & 46.0 \\
\hline Hypercholesterolemia (\%) & 60.9 & 48.4 & 52.2 & 50.0 & 50.2 & 48.4 \\
\hline High blood pressure (\%) & 46.9 & 43.0 & 48.4 & 57.7 & 60.7 & 68.2 \\
\hline
\end{tabular}

ear trend $(\mathrm{P}=0.41$ for NHS participants; $\mathrm{P}=0.22$ for HPFS participants). Among participants who had ever smoked, however, there was a nonlinear $\mathrm{J}$-shaped trend in the combined cohort of men and women and in the cohort of women $(\mathrm{P}<0.001$ for NHS participants) but not in the cohort of men ( $\mathrm{P}=0.72$ for HPFS participants).

Significant effect modification according to age at diagnosis was observed $(\mathrm{P}<0.001$ for interaction) (Table S1 in the Supplementary Appendix). Among adults younger than 65 years of age at diagnosis, there was a direct linear relationship between BMI and all-cause mortality $(\mathrm{P}<0.001$ for linear trend among total participants, those who had never smoked, and those who had ever smoked). In contrast, a direct linear trend among participants 65 years of age or older at diagnosis was observed only among those who had never smoked $(\mathrm{P}=0.04)$, and among participants who had ever smoked, a significantly increased risk of death was observed only in the lowest BMI category (hazard ratio, 1.89; 95\% CI, 1.32 to 2.71).

The results of the analyses that assessed residual confounding by smoking status and reverse causation are depicted in Figures 1A through 1F. Exclusion of participants who died in 


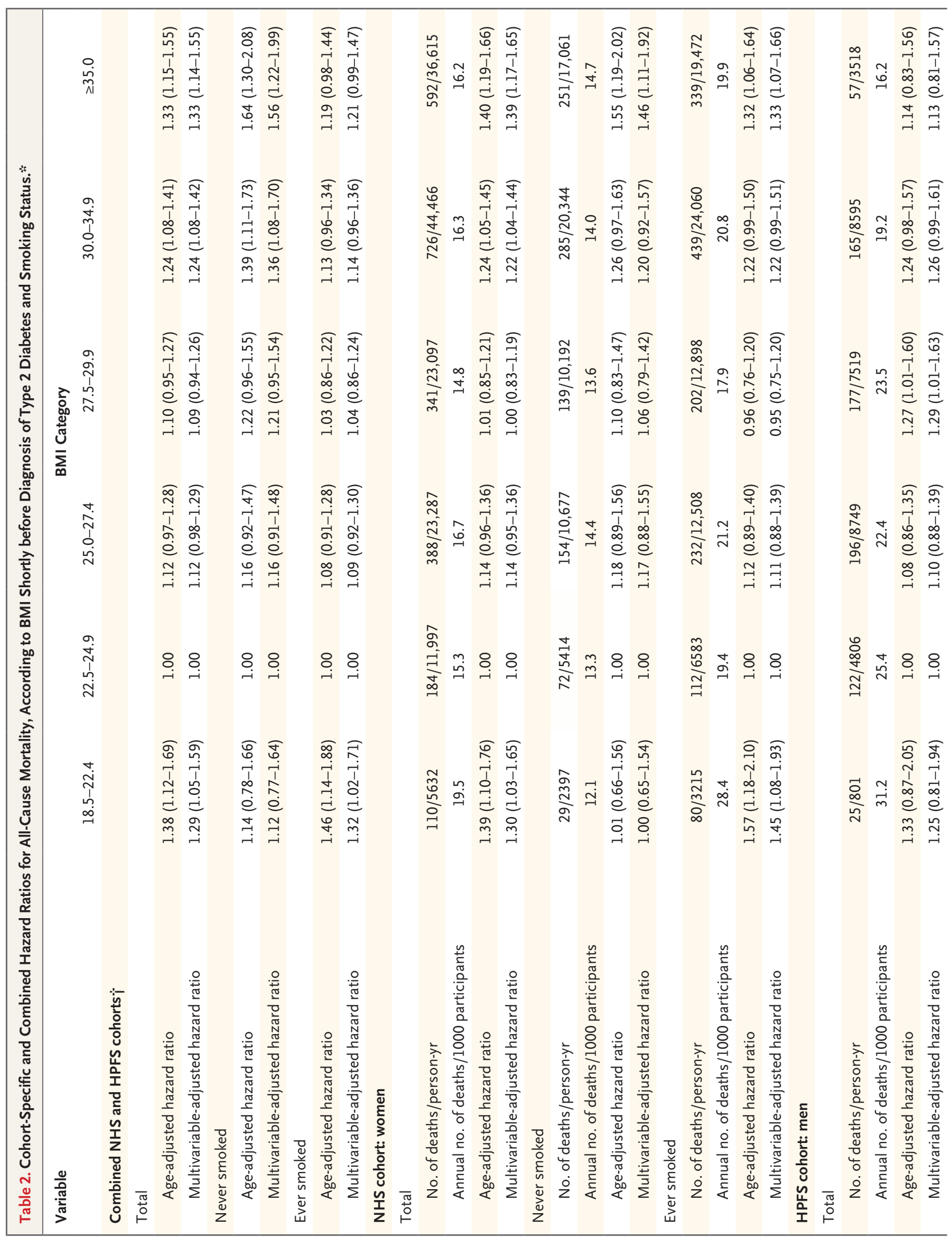




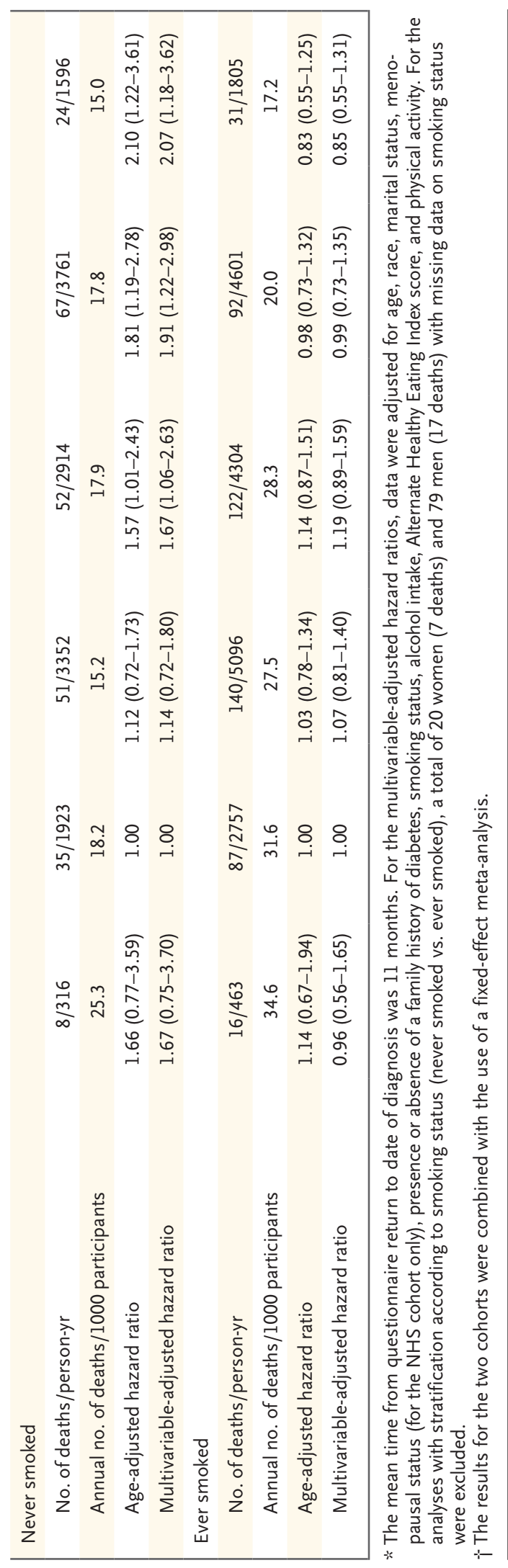

the first 4 years of follow-up (a total of 227 participants: 78 who had never smoked and 149 who had ever smoked) (Fig. 1B, 1D, and 1F, respectively) resulted in a monotonic positive association between BMI and death among participants who had never smoked, and the results did not differ substantially from those of the primary analysis. Exclusion of participants with weight loss of more than 1 BMI unit before a diabetes diagnosis, adjustment for baseline hypertension or hypercholesterolemia, and adjustment for year of diabetes diagnosis produced similar results (data not shown). The tests for the proportional-hazards assumption did not indicate a violation in either cohort. Age-adjusted survival curves are depicted in Figures S2A through S2D in the Supplementary Appendix.

Using the traditional cutoff points for the BMI categories of normal weight, overweight, and obesity (Table S2 in the Supplementary Appendix) and correcting errors in self-reported weight and height (Table S3 in the Supplementary Appendix) did not significantly change the results.

\section{CAUSE-SPECIFIC MORTALITY}

We assessed the relationship between BMI just before a diabetes diagnosis and deaths due to cardiovascular disease (941 deaths), cancer (784 deaths), and other causes (e.g., respiratory diseases, renal disease, suicide, and accidents; 1358 deaths) (Fig. 2A, 2B, and 2C; and Table S4 in the Supplementary Appendix). There was a significant direct linear relationship between BMI and cardiovascular mortality among all participants ( $\mathrm{P}<0.001$ for linear trend) and among those who had never smoked $(\mathrm{P}=0.004)$, but the relationship appeared to be attenuated among those who had ever smoked $(\mathrm{P}=0.02)$. In the lowest BMI category (18.5 to 22.4), a significant increase in cancer mortality was seen among all participants (hazard ratio, 1.51; 95\% CI, 1.00 to 2.28 ) and among those who had ever smoked (hazard ratio, 1.87; 95\% CI, 1.15 to 3.04) but not among those who had never smoked (hazard ratio, 0.83; $95 \%$ CI, 0.34 to 2.05). The relationship between BMI and mortality from other causes appeared to be J-shaped for all participants.

\section{DISCUSSION}

Our analyses of data from two large, long-term, prospective cohort studies indicate a J-shaped as- 
sociation between BMI immediately before a diagnosis of type 2 diabetes and all-cause mortality. This relationship was linear among participants who had never smoked but was nonlinear among those who had ever smoked. We did not observe a benefit of excess adiposity with regard to the risk of death; thus, our findings support the current recommendation that patients with diabetes achieve or maintain a normal weight. ${ }^{28}$

Although our findings are largely consistent with the results of previous analyses in the general population, ${ }^{1-4}$ they contradict the results of several studies of BMI and mortality among participants with diabetes. Prior studies largely suggest inverse, ${ }^{10} \mathrm{~J}$ - or U-shaped, ${ }^{11,29,30}$ or flat or null associations ${ }^{9,31}$; however, notable limitations include a short follow-up duration, ${ }^{9,11,30}$ a small number of deaths, ${ }^{10,29,31,32}$ and a lack of analyses assessing biases from smoking or undiagnosed chronic diseases. ${ }^{9-11,29-32}$ The majority of these studies involved patients who already had diabetes, with BMI assessed up to several decades after the diagnosis; these factors substantially increase susceptibility to reverse-causation bias. ${ }^{9,29-32}$

Recently, Carnethon et al. ${ }^{10}$ analyzed pooled data from five large U.S. cohorts and concluded that adults who were of normal weight at the time of a diabetes diagnosis had a risk of death that was twice as high as that among their overweight or obese counterparts (hazard ratio, 2.01; $95 \% \mathrm{CI}, 1.44$ to 2.81); however, several of the limitations outlined above apply to this study. Relatively low statistical power (449 total deaths) limited their BMI classification to two broad and heterogeneous exposure groups (participants with a BMI of 18.5 to 24.9 and those with a BMI $\geq 25.0$ ). Subgroup analyses were also underpowered, such that conclusions could not be drawn. In addition, BMI was measured after the diabetes diagnosis for many participants, allowing additional bias from the initiation of diabetes treatment or the progression of other underlying illnesses..$^{10}$

The attenuated relationship between BMI and mortality among smokers has frequently been observed in the general population..$^{3,4,14,15}$ It is unclear whether this effect modification represents biologic differences between smokers and nonsmokers or is largely due to bias. ${ }^{13}$ Additional studies are needed to answer this question.

In our study, effect modification according to age at diagnosis indicated a direct linear trend among participants younger than 65 years of age but a null or weakened linear association among participants 65 years of age or older. These findings, which are consistent with the results of previous studies involving participants with type 2 diabetes $^{32}$ and the general population, ${ }^{1,33}$ may reflect well-known limitations in analyses of mortality among older persons, including an increased prevalence of coexisting chronic diseases, which increases the potential for reverse-causation bias; an increased prevalence of competing risk factors, which reduces the proportional effect of a single factor; and decreased validity of BMI as a measure of adiposity owing to age-related declines in muscle mass and wasting. ${ }^{34}$ It has also been suggested that excess adiposity may confer a metabolic advantage and improved survival among the elderly. Therefore, caution should be taken in interpreting the results among the older participants.

Our findings with respect to the relationship between BMI and mortality due to specific causes are consistent with those of prior studies conducted in the general population. ${ }^{2-4,14,15}$ Among participants who had never smoked, the relationship of BMI to both cardiovascular mortality and cancer mortality appeared to be monotonic and linear. No significant association was observed between any BMI category and the risk of death from cardiovascular disease among participants who had ever smoked; however, participants in the lowest BMI category who had ever smoked had a significantly elevated risk of death from cancer.

Proposed biologic mechanisms of the alleged obesity paradox include an increased genetic influence and more severe diabetes among normal-weight persons with diabetes or the effect of a "metabolically obese normal weight" phenotype. ${ }^{35,36}$ However, normal-weight participants in our cohort were no more likely to report diabetes symptoms or coexisting chronic diseases or to require insulin than were overweight or obese participants. In contrast, normal-weight participants were more likely to be smokers and to have lost weight before a diagnosis of diabetes. Comparisons with this heterogeneous normal-weight group may therefore underestimate the risk of death among the overweight and obese.

Strengths of our study include the large sample (3083 deaths among 11,427 adults with incident diabetes), permitting detailed exami- 


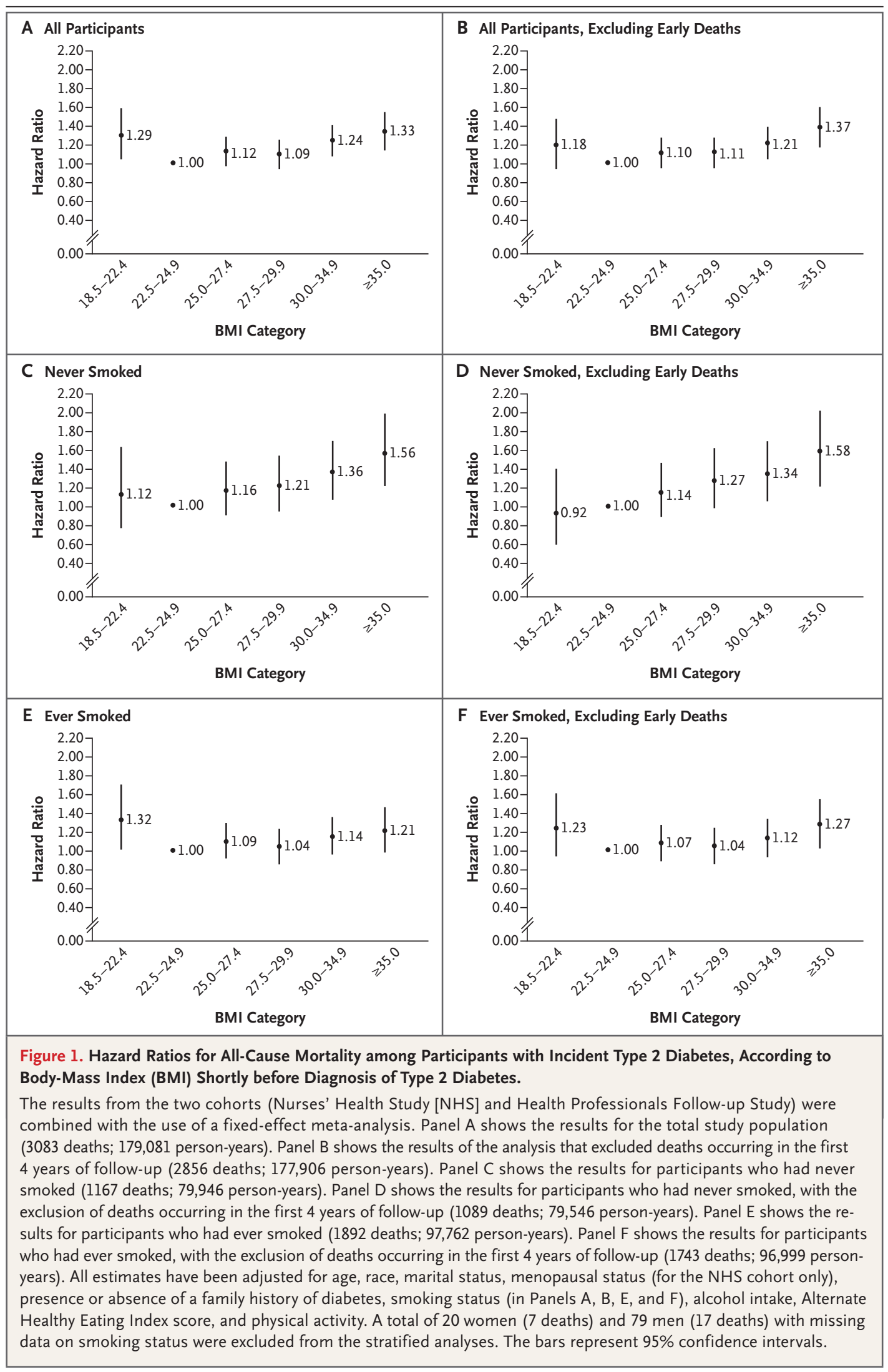

N ENGL J MED 370;3 NEJM.ORG JANUARY 16, 2014

The New England Journal of Medicine

Downloaded from nejm.org on May 2, 2016. For personal use only. No other uses without permission.

Copyright (C) 2014 Massachusetts Medical Society. All rights reserved. 


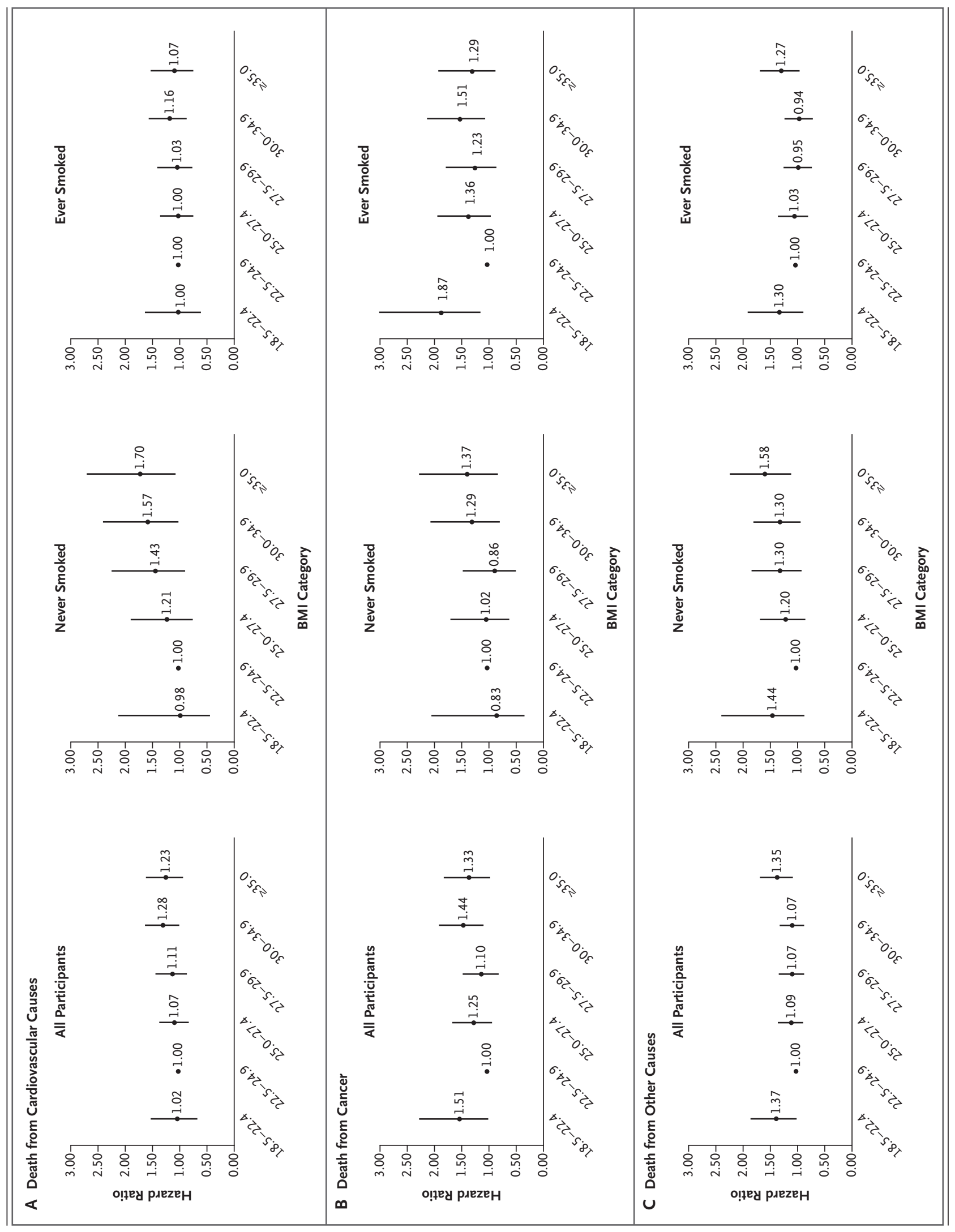


Figure 2 (facing page). Hazard Ratios for Cause-Specific Mortality among Participants with Incident Type 2 Diabetes, According to BMI Shortly before Diagnosis of Type 2 Diabetes.

The results from the two cohorts (NHS and Health Professionals Follow-up Study) were combined with the use of a fixed-effect meta-analysis. The numbers of personyears were 179,081 for all participants, 79,546 for those who had never smoked, and 97,762 for those who had ever smoked. Panel A shows cardiovascular mortality in the total study population ( 941 deaths), among participants who had never smoked (340 deaths), and among those who had ever smoked (592 deaths). Panel B shows cancer mortality in the total study population (784 deaths), among participants who had never smoked (266 deaths), and among those who had ever smoked (514 deaths). Panel G shows mortality from other causes in the total study population (1358 deaths), among participants who had never smoked (561 deaths), and among those who had ever smoked (786 deaths). All estimates have been adjusted for age, race, marital status, menopausal status (for the NHS cohort only), presence or absence of a family history of diabetes, smoking status (among all participants and those who had ever smoked), alcohol intake, and Alternate Healthy Eating Index score. A total of 20 women and 79 men with missing data on smoking status were excluded from the stratified analyses (24 total deaths, including 9 from cardiovascular causes, 4 from cancer, and 11 from other causes). The bars represent $95 \%$ confidence intervals.

nation across multiple BMI categories and key analyses to address potential biases. Prospectively measured body weight, documented just before or at the time of a diabetes diagnosis, prevents misclassification from weight change due to early pharmacologic treatments or lifestyle changes shortly after diagnosis. Enrollment of health professionals has proved beneficial with respect to the reliability and validity of self-reported health-related exposures and outcomes, and it reduces confounding by educational and socioeconomic factors.

Limitations of the study include the reliance on self-reported weight measures, although erroneous reporting was shown to be very minimal in validation studies, and corrections of errors in BMI measurement produced similar findings. Information on weight was obtained an average of 11 months before diagnosis as a proxy for the weight at diagnosis, but this is unlikely to have resulted in appreciable error. Finally, the relative homogeneity of the NHS and HPFS cohorts may limit the generalizability of our findings to other racial and ethnic groups.

In conclusion, our results indicate a J-shaped relationship between BMI at the time of a diabetes diagnosis and the risk of death from all causes, with the lowest risk observed among normal-weight participants with a BMI of 22.5 to 24.9. Among participants who had never smoked, there was a direct linear relationship between BMI and mortality, whereas a nonlinear relationship was observed among those who had ever smoked. There was no evidence of a protective effect of overweight or obesity on mortality. In addition, given the relationship of overweight and obesity to other critical public health end points (e.g., cardiovascular disease and cancer), the maintenance of a healthy body weight should remain the cornerstone of diabetes management, irrespective of smoking status. Further evidence is needed to corroborate our findings in other populations.

Supported by grants from the National Institutes of Health (UM1 CA167552, UM1 CA176726, P01 CA87969, R01 HL034594, P01 CA055075, DK58845, CA55075, CA87969, HL34594, P30 DK46200, and 1U54CA155626-01) and the American Diabetes Association (7-12-MN-34).

Disclosure forms provided by the authors are available with the full text of this article at NEJM.org.

We thank the participants in the Health Professionals Follow-up Study and the Nurses' Health Study for their continuing support, as well as our colleagues working in these studies for their contributions.

\section{REFERENCES}

1. Adams KF, Schatzkin A, Harris TB, et al. Overweight, obesity, and mortality in a large prospective cohort of persons 50 to 71 years old. N Engl J Med 2006;355:763-78.

2. Chen Z, Yang G, Offer A, et al. Body mass index and mortality in China: a 15year prospective study of $220000 \mathrm{men}$. Int J Epidemiol 2012;41:472-81.

3. Berrington de Gonzalez A, Hartge P, Cerhan JR, et al. Body-mass index and mortality among 1.46 million white adults. N Engl J Med 2010;363:2211-9. [Erratum, N Engl J Med 2011;365:869.]
4. Zheng W, McLerran DF, Rolland B, et al. Association between body-mass index and risk of death in more than 1 million Asians. N Engl J Med 2011;364:719-29. 5. Schmidt D, Salahudeen A. The obesitysurvival paradox in hemodialysis patients: why do overweight hemodialysis patients live longer? Nutr Clin Pract 2007;22:11-5. 6. Uretsky S, Messerli FH, Bangalore S, et al. Obesity paradox in patients with hypertension and coronary artery disease. Am J Med 2007;120:863-70.

7. Lavie CJ, Milani RV, Ventura HO,
Romero-Corral A. Body composition and heart failure prevalence and prognosis: getting to the fat of the matter in the "obesity paradox." Mayo Clin Proc 2010; 85:605-8.

8. Doehner W, Erdmann E, Cairns R, et al. Inverse relation of body weight and weight change with mortality and morbidity in patients with type 2 diabetes and cardiovascular co-morbidity: an analysis of the PROACTIVE study population. Int J Cardiol 2012;162:20-6.

9. McEwen LN, Karter AJ, Waitzfelder BE, 
et al. Predictors of mortality over 8 years in type 2 diabetic patients: Translating Research Into Action for Diabetes (TRIAD). Diabetes Care 2012;35:1301-9.

10. Carnethon MR, De Chavez PJ, Biggs $M L$, et al. Association of weight status with mortality in adults with incident diabetes. JAMA 2012;308:581-90. [Erratum, JAMA 2012;308:2085.]

11. Logue J, Walker JJ, Leese G, et al. Association between BMI measured within a year after diagnosis of type 2 diabetes and mortality. Diabetes Care 2013;36:887-93.

12. Florez H, Castillo-Florez S. Beyond the obesity paradox in diabetes: fitness, fatness, and mortality. JAMA 2012;308: 619-20.

13. Manson JE, Stampfer MJ, Hennekens $\mathrm{CH}$, Willett WC. Body weight and longevity: a reassessment. JAMA 1987;257:353-8. 14. Manson JE, Willett WC, Stampfer MJ, et al. Body weight and mortality among women. N Engl J Med 1995;333:677-85.

15. Pischon T, Boeing H, Hoffmann K, et al. General and abdominal adiposity and risk of death in Europe. N Engl J Med 2008;359:2105-20. [Erratum, N Engl J Med 2010;362:2433.]

16. Hu FB. Obesity epidemiology. New York: Oxford University Press, 2008.

17. Colditz GA, Manson JE, Hankinson SE. The Nurses' Health Study: 20-year contribution to the understanding of health among women. J Womens Health 1997;6: 49-62.

18. Rimm EB, Giovannucci EL, Willett WC, et al. Prospective study of alcohol consumption and risk of coronary disease in men. Lancet 1991;338:464-8.
19. Classification and diagnosis of diabetes mellitus and other categories of glucose intolerance. Diabetes 1979;28:1039-57.

20. Report of the Expert Committee on the Diagnosis and Classification of Diabetes Mellitus. Diabetes Care 1997;20:1183-97.

21. Manson JE, Rimm EB, Stampfer MJ, et al. Physical activity and incidence of noninsulin-dependent diabetes mellitus in women. Lancet 1991;338:774-8.

22. Hu FB, Leitzmann MF, Stampfer MJ Colditz GA, Willett WC, Rimm EB. Physical activity and television watching in relation to risk for type 2 diabetes mellitus in men. Arch Intern Med 2001;161: 1542-8.

23. Rimm EB, Stampfer MJ, Colditz GA, Chute CG, Litin LB, Willett WC. Validity of self-reported waist and hip circumferences in men and women. Epidemiology 1990;1:466-73.

24. Rich-Edwards JW, Corsano KA, Stampfer MJ. Test of the National Death Index and Equifax Nationwide Death Search. Am J Epidemiol 1994;140:1016-9.

25. Stampfer MJ, Willett WC, Speizer FE et al. Test of the National Death Index. Am J Epidemiol 1984;119:837-9.

26. Chiuve SE, Fung TT, Rimm EB, et al Alternative dietary indices both strongly predict risk of chronic disease. J Nutr 2012;142:1009-18.

27. Durrleman S, Simon R. Flexible regression models with cubic splines. Stat Med 1989;8:551-61.

28. American Diabetes Association. Standards of medical care in diabetes - 2013. Diabetes Care 2013;36:Suppl 1:S11-S66.

29. Ross C, Langer RD, Barrett-Connor E.
Given diabetes, is fat better than thin? Diabetes Care 1997;20:650-2.

30. Khalangot M, Tronko M, Kravchenko V, Kulchinska J, Hu G. Body mass index and the risk of total and cardiovascular mortality among patients with type 2 diabetes: a large prospective study in Ukraine. Heart 2009;95:454-60.

31. Chaturvedi N, Fuller JH. Mortality risk by body weight and weight change in people with NIDDM. Diabetes Care 1995;18:766-74.

32. Zoppini G, Verlato G, Leuzinger C, et al. Body mass index and the risk of mortality in type II diabetic patients from Verona. Int J Obes Relat Metab Disord 2003; 27:281-5.

33. Calle EE, Thun MJ, Petrelli JM, Rodriguez C, Heath CW Jr. Body-mass index and mortality in a prospective cohort of U.S. adults. N Engl J Med 1999;341:1097105.

34. Manson JE, Bassuk SS, Hu FB, Stampfer MJ, Colditz GA, Willett WC. Estimating the number of deaths due to obesity: can the divergent findings be reconciled? J Womens Health (Larchmt) 2007;16:168-76.

35. Perry JR, Voight BF, Yengo L, et al. Stratifying type 2 diabetes cases by BMI identifies genetic risk variants in LAMA1 and enrichment for risk variants in lean compared to obese cases. PLoS Genet 2012;8(5):e1002741.

36. Conus F, Rabasa-Lhoret R, Péronnet F. Characteristics of metabolically obese normal-weight (MONW) subjects. Appl Physiol Nutr Metab 2007;32:4-12.

Copyright (@) 2014 Massachusetts Medical Society.

SPECIALTIES AND TOPICS AT NEJM.ORG

Specialty pages at the Journal's website (NEJM.org) feature articles in cardiology, endocrinology, genetics, infectious disease, nephrology, pediatrics, and many other medical specialties. These pages, along with collections of articles on clinical and nonclinical topics, offer links to interactive and multimedia content and feature recently published articles as well as material from the NEJM archive (1812-1989). 